\title{
Esophageal Anastomotic Leak, CTCAE
}

National Cancer Institute

\section{Source}

National Cancer Institute. Esophageal Anastomotic Leak, CT CAE. NCI Thesaurus. Code C143451.

A finding of leakage due to breakdown of an esophageal anastomosis (surgical connection of two separate anatomic structures). 